\title{
The Wider Impacts of High-Technology Employment: Evidence from U.S. Cities
}

\author{
Tom Kemeny, Queen Mary, University of London \\ Taner Osman, University of California, Los Angeles
}

\begin{abstract}
This is the accepted version of a paper published in Research Policy in June 2018. Please find and cite the official, published version: https://doi.org/10.1016/j.respol.2018.06.005
\end{abstract}

\begin{abstract}
:
Innovative, high-technology industries are commonly described as drivers of regional development. 'Tech' workers earn high wages, but they are also said to generate knock-on effects throughout the local economies that host them, spurring growth in jobs and wages in nontradable activities. At the same time, in iconic high-tech agglomerations like the San Francisco Bay Area, the home of Silicon Valley, the success of the tech industry creates tensions, in part as living costs rise beyond the reach of many non-tech workers. Across a large sample of U.S. cities, this paper explores these issues systematically. Combining annual data on wages, employment and prices from the Quarterly Census of Employment and Wages, the Department of Housing and Urban Development and the Consumer Price Index, it estimates how growth in tradable tech employment affects the real, living-cost deflated wages of local workers in nontradable sectors. Results indicate that high-technology employment has significant, positive, but modest effects on the real wages of workers in nontradable sectors. These effects appear to be spread consistently across different kinds of nontradable activities. In terms of substantive wider impacts, tech appears benign, though fairly ineffectual.
\end{abstract}

Keywords: high-technology, inequality, real wages, nontradable services; specialization, housing supply

JEL codes: E24; J21; J31; L86; O18; R11; R31

Acknowledgments: For helpful suggestions, the authors thank Neil Lee; Max Nathan; Chris Esposito; Michael Storper, Maria Savona, David Soskice, Aaron Reeves, Billie ElmqvistThuren, Henry Overman, Amos Zehavi, Pedro Martins, Martha Prevezer participants at meetings of the Regional Studies Association, the Association of American Geographers, and GEOINNO2018. We are very grateful to Sergio Petralia for sharing historical patent data. All errors are our own. 


\section{Introduction}

In 2017, the online retailer Amazon announced it would build a second headquarters, dubbed HQ2, somewhere in North America. Policymakers throughout the US and Canada clamored to have their city chosen, reportedly wooing the company with offers of as much as $\$ 7 \mathrm{bn}$ in state and local tax breaks and other incentives (CNN Money, 2018). Though the numbers involved are unusual, the contours of the story are not unique. Scholars widely hold that innovative, hightechnology industries drive regional development, and it is equally commonplace for policymakers to expend great effort to attract them to their localities (Clark, 1972; Duranton, 2011). 'Tech' workers command high wages, and as such their presence contributes to regional prosperity. Above and beyond this direct effect, tech industries are thought to generate wider economic benefits in the local economies that host them. Durable employment growth in tech and other tradable sectors raises demand for local nontradable activities, such as health care, restaurants and dry cleaners. Higher demand for nontradables can be expressed through job creation as well as, potentially, higher pay. Since wages in tech are on average higher than in many other tradable industries, one might expect indirect benefits from tech to be comparatively large.

Still, dark clouds hang over this sunny-seeming picture. Cities hosting larger concentrations of workers in tech and other skill-intensive activities have also witnessed faster growth in local prices (Shapiro, 2006; Florida 2017). Studies of the most iconic technology clusters in the U.S. highlight the deleterious effects of rising costs, especially housing, on workers whose jobs support tech and other traded sectors (Schafran, 2013; Hyra, 2015). Ganong and Shoag (2017) illustrate the point, observing that, while janitors working in New York City in 2010 earned nearly one third more in nominal pay than their counterparts in Deep South States, after adjusting for housing prices they earn six percent less. This raises questions about the narrative that tech employment generates outcomes that are "unambiguously positive" (Moretti and Thulin, 2013, p.343). They also confirm a need to measure not just job quantity but also quality (Feldman et al., 2016), the latter reflected in part by real (cost-adjusted) wages.

Motivated by this debate, the present paper aims to better understand the links between tech and the economic welfare of workers in nontradable sectors - those sectors of the economy that are 
primarily oriented towards local consumption. Ours is the first known paper that measures the effects of local employment changes in tradable high-technology activities on the real wages of workers in local nontradables. Using data on a large sample of U.S. metropolitan areas, we test three hypotheses. First and most generally, we test the hypothesis that permanent expansions in high technology employment raise the real wages of workers in local nontradables. Second, given the emphasis placed on tech as a uniquely important catalyst for regional development, we consider whether the indirect impacts of tech tradables are larger than those that flow from nontech tradable employment. Third, guided by anecdotes suggesting that tech workers disproportionately consume particular kinds of nontradables, especially wage-, skill- and creativity-intensive activities like fine dining, we seek to determine whether tech has a larger impact on activities that are rich in such characteristics.

To test these hypotheses, we combine annual industry-data drawn from the U.S. Bureau of Labor Statistics' (BLS) Quarterly Census of Employment and Wages (QCEW) with information on local prices from the Department of Housing and Urban Development (HUD) and the BLS' Consumer Price Index for All Urban Consumers (CPI-U). Over a study period ranging from 2001 to 2015, we estimate how annual changes in metropolitan tradable high-technology employment are associated with changes in the average real wages of workers in local nontradable sectors. We leverage the panel nature of our data to eliminate bias from timeinvariant unobserved city-specific factors as well as economy-wide dynamics. We aim to account for the effects of idiosyncratic shocks using two instruments: a shift-share measure of predicted tech employment (Bartik, 1991), and a measure of local patents per capita accumulated during the $19^{\text {th }}$ century.

We find stable and consistent evidence that growth in local tech employment augments the real wages earned by workers in nontradable sectors. However, the influence of tech is minor. Across a range of models with different controls and estimation strategies, we find that a ten percent increase in local tech employment raises the annual real wages of workers in nontradable activities by between 0.1 and 0.7 percent. With regard to the second hypothesis, we find that tech and non-tech tradable employment have roughly comparable impacts on nontradable real wages. Regarding our third hypothesis, we decompose the nontradable sector and find little 
unambiguous evidence that growth of the tech sector engenders demand for highly paid nontradables. Further, we find little clear support for the proposition that demand derived from growth in local tech employment is directed towards more 'creative' or 'original' nontradable activities, though we do find that workers in more skill-intensive nontradables reap moderately higher returns. We interpret these last pieces of evidence cautiously, recognizing that industrial categories may not offer sufficient differentiation across industries of interest.

Taken together, the evidence we produce indicates that there are indeed wider benefits to be enjoyed from growth in a region's high-technology employment, but that these benefits are likely to be small. Policy efforts aimed at boosting tech employment are not likely to powerfully augment the economic welfare of those working in local-serving nontradables. On the other hand, we find no support for the idea that tech industry growth systematically decreases these workers' real wages.

\section{LITERATURE REVIEW}

Innovative, high-technology activities have long enjoyed a privileged position among researchers and policymakers concerned with economic development (Clark, 1972; Malecki, 1981; Scott and Storper, 1987; Duranton 2011; Howells, 2005; Block and Keller, 2009; Storper et al., 2015). Nonroutine high-technology activities tend to be strongly localized in space, as firms and workers congregate to match with each other and to efficiently produce and exchange tacit knowledge (Storper and Walker, 1989; Glaeser et al, 1992; Saxenian, 1994; Chatterji et al, 2014).

The increasing importance of high-technology goods and services has stimulated job growth in these industries, through the expansion of existing firms and the birth of new ventures. Growth in this sector can have direct and indirect effects on the localities that play host to it. First and most directly, it will expand the local employment base. And as workers in high-technology industries tend to be well paid, growth in tech employment is likely to increase local per capita incomes. Such direct income effects can be large. At the extreme, consider the tech boom of 1994-2000. Over this period, Galbraith and Hale (2004) document that the California counties of San Mateo, 
Santa Clara and San Francisco (all in the San Francisco Bay Area that contains Silicon Valley), as well Washington's King County (home to Microsoft and Amazon) together accounted for nearly all of the growth in between-county income inequality.

The indirect effects of tech employment are subtler. To understand them, one must first distinguish between tradable and nontradable economic activity. Tradable goods are those produced to serve national, and potentially global markets, and as such face prices that are not defined locally. Many such activities are subject to internal or external increasing returns to scale in production, and consequently will tend towards a high degree of geographic concentration. Meanwhile, nontradable activities serve local needs and face local prices. As described in the introduction, these include goods and services like health care, dry cleaning, and restaurants. Nontradables comprise the majority of local employment; in the U.S. context, they are also responsible for the bulk of employment growth in recent years (Spence and Hlatshwayo, 2012).

Using export-base theory and input-output methods, scholars have long considered that local tradable and nontradable employment are linked (North, 1955; Richardson, 1985). Moretti (2010) provides a theoretical update, describing a general equilibrium framework under which the national economy is comprised of a system of cities in which workers choose locations. Each city contains a mix of tradable and nontradable activities. A positive shock to local labor demand in the tradable sector stimulates demand for workers in nontradables. This will lead to new jobs for dry cleaners, medical technicians and chefs, as well as higher pay for workers in these sectors. As Moretti and Thulin (2013) outline, the extent to which expansions of the tradable sector produce job growth as opposed to wage growth in nontradables depends on the supply of housing in a location, as well as on potential migrants' responsiveness to new opportunities. Locations facing strong constraints on housing supply will experience higher nominal wage growth and lower job creation. Meanwhile, all else equal, a greater elasticity of migration will tip the balance towards larger job multipliers and weaker upward pressure on wages (Hsieh and Moretti 2016). On the basis that high-productivity tech work produces a larger expansion in local income relative to other tradables, growth in tech ought to create especially large demand for nontradables. 
There are some other reasons why workers in nontradable sectors will experience pay growth as a consequence of an expansion in tradable employment. One is that workers in tradables may generate knowledge externalities that spill over to workers in nontradables, making the latter more productive. These effects ought to be somewhat minor, in that, for a wide range of nontradable activities such as barbers, dry cleaners, and restaurants, proximity to software engineering and pharmaceutical development likely offers very modest potential for productivity enhancement. Baumol's (1967) 'cost disease' represents another potential channel. Observing that the wages of workers in nontradable sectors like education have risen despite significant increases in productivity, Baumol suggests that pay must be indexed to rates of wage growth in productive sectors, as a means of ensuring that teachers do not defect to activities where productivity, and hence pay, are rising. To the extent that this mechanism is in operation, in the present context it is essential to note that not all workers are equally likely to switch to the productive sector. The average barber is less likely than a physics teacher to become a software engineer.

Evidence tracing the wider impacts of tech tradable employment has been almost entirely focused on measuring job multipliers. A growing literature has documented the existence of multipliers flowing from various kinds of tradable activities in a range of countries (Moretti, 2010; de Blasio and Menon, 2011; Moretti and Thulin, 2013; Fleming and Measham, 2014; van Dijk, 2016, 2018; Frocrain and Giraud, 2017). The classic finding from this literature comes from Moretti (2010), in which, using data for the 1980s and 1990s, he finds that the addition of one manufacturing job generates 1.6 local nontradable jobs, whereas a new job in hightechnology manufacturing generates nearly 5 local jobs in nontradable activities.

Surprisingly, given renewed interest in this topic, there is nearly no evidence tracing the effects of tech or other tradable employment on nontradable wages. In the U.S. context, there is at least one strong reason to explore this channel: internal migration has slowed since 1980, a trend that cuts across a wide range of demographic features (Molloy et al, 2011). As a consequence, at least some of the pressure from rising demand ought to raise the nominal wages of workers in nontradable activities. Only a few studies exist that investigate how high-technology employment affects the wages of workers beyond tech. Echeverri-Carroll and Ayala (2009) and 
Lee and Rodriguez-Pose (2016) show that tech employment in U.S. metropolitan areas is associated with higher nominal wages for workers without college degrees; the latter also finds no association between tech and the share of local residents falling below the national poverty line. Studying the UK, Lee and Clarke (2017) show that tech employment is associated with growth in poorly paid jobs requiring relatively unskilled labor. A little more loosely related, Fowler and Kleit (2013) find ambiguous relationships between concentrations of tradable activity and the local incidence of poverty.

No known work has captured how high-technology or other tradable activities affect the real wages for workers in local nontradable sectors. There are good reasons why this may be important. Longstanding patterns of interstate and inter-metropolitan income convergence more or less stopped after 1980 (Drennan et al, 1996; Giannone, 2017). While we lack consensus on the deep causal explanations for this shift, one proximate cause is a skill-biased sorting process, whereby higher- and lower-skilled workers are increasingly concentrating in different locations (Shapiro, 2006). Since 1980, high-skill workers are increasingly concentrated in highproductivity, high-amenity locations, where the already-elevated cost of housing has increased more sharply than in locations with lower shares of college graduates (Diamond, 2016). While living costs in high-productivity locations reduce cost-blind estimates of national income inequality (Moretti, 2013), they also highlight the need to consider effects of high-technology employment on real, not nominal wages.

This should come as little surprise to scholars and advocacy organizations long concerned with processes of gentrification, displacement and neighborhood change (National Urban Coalition, 1978; Zuk et al, 2015). This methodologically varied field of research has documented how the renewed urbanization of skilled workers has generated winners and losers. A clear consensus indicates that the housing security of lower-income workers, many of whom work in the nontradable sector of the economy, can be precarious in the face of sudden changes in the nature of urban housing markets. Yet much of this work is ethnographic in nature, and as a consequence questions of generalizability remain underexplored. 
These issues prompt the following two hypotheses:

\title{
H1: A permanent expansion in high technology employment should raise the real wages of workers in local nontradable sectors.
}

\author{
H2: Since the effects of tech employment on nontradable wages is through derived demand, \\ and since tech wages are higher than other tradables, the effects of tech on nontradable \\ wages should be large relative to that of other tradables.
}

It is also possible that the wage effects of local tech expansions depend on the nature of nontradable activities. There is little formal theory and no known systematic evidence identifying specific kinds of nontradables favored by tech workers. It may be that consumption baskets of workers in tech resemble those in other activities. On the other hand, anecdotes abound linking tech to particular nontradables, for instance, fine dining, 'third wave' coffee shops like Blue Bottle and Bulletproof (Mashable, 2017), or the mindfulness on offer in Big Sur's Esalen (New York Times, 2017) and other more prosaic outlets. While upholding skepticism about the generalizability of such anecdotes, in our third hypothesis we entertain the notion of possible biases in consumption among tech workers, specifically towards industries defined by higher wages, and or those marked by higher levels of skill, originality or creativity:

\section{H3: The effects of tech employment may vary according to the task and wage profile of specific subsectors of nontradable activity.}

In the next section, we describe our approach to answering these questions.

\section{EMPIRICAL APPROACH}

In order to evaluate the relationship between local employment in the high-technology sector and the real wages of workers in local nontradable sectors, we estimate the following regression equation: 


$$
\ln \left(R W_{c t}^{N T}\right)=\beta_{0}+\beta_{1} \ln \left(E_{c t}^{T}\right)+\gamma X_{c t}^{\prime}+\mu_{c}+\eta_{t}+v_{c t}
$$

where $\ln (R W)$ describes the log of real (local cost-deflated) wages of workers in nontradables, captured by the superscript $N T$, in city $c$ and time $t^{1}{ }^{1}$ The $\log$ of employment in high-tech tradable sectors is captured by $\ln \left(\mathrm{E}^{T}\right)$, and $X^{\prime}$ is a vector of relevant time-varying city characteristics. $\mu$ is a city-specific fixed effect, whose purpose is to absorb bias from unobserved but relatively stationary local features, while $\eta$ is a year fixed effect, included to capture timevarying but economy-wide shocks, such as the Great Recession. The standard random error term is represented by $v$. The key parameter to be estimated is $\beta_{1}$, measuring the effect of hightechnology employment.

Applying the fixed effects estimator, Equation 1 measures how the average annual real wages of workers in local nontradables respond to changes in the level of high-technology employment around them. It does so while accounting for major sources of spurious correlation that might otherwise bias estimates. However, estimates remain vulnerable to unobserved localized shocks that happen to be correlated with the level of high-technology employment, and that also shape real wages. For instance, consider a local government that enacts a law imposing a congestion tax on drivers. Workers' commuting costs rise as a consequence, and some proportion of these costs get capitalized into wages (Timothy and Wheaton 2001). To the extent that this hypothetical location simultaneously experiences an expansion in their tech sector, estimates of the effects of tech on nontradable wages will be upwardly biased. To absorb bias from such idiosyncratic shocks we use instrumental variables. We consider two candidate instruments. The first is a dynamic 'shift-share' measure, common in labor and regional economics (i.e. Bartik, 1991, Ottaviano and Peri, 2006). Our aim is to capture the exogenous component of local demand for high-technology sectors, as follows:

$$
\widehat{E_{c, t}^{T}}=E_{c, t-1}^{T}\left[1+\frac{\left(E_{U S, t}^{T}-E_{c, t}^{T}\right)-\left(E_{U S, t-1}^{T}-E_{c, t-1}^{T}\right)}{\left(E_{U S, t-1}^{T}-E_{c, t-1}^{T}\right)}\right]
$$

\footnotetext{
${ }^{1}$ Throughout the paper, we use terms like 'city', 'region' and 'metropolitan area' interchangeably to refer to metropolitan Core-Based Statistical Areas (CBSAs), which are defined by the Office of Management and Budget to reflect economic integration.
} 
where $E_{U S}$ denotes national employment levels, and all other variables remain as above. Equation 2 arrives at the 'expected' level of local high-tech employment in period $t$ by multiplying initial local tech tradable employment by the national growth rate for employment in the sector between $t-1$ and $t$. Because national growth rates include the region in question, and could therefore be driven by them, we follow Faggio and Overman (2014) in subtracting local employment from national employment.

To grasp the intuition behind our instrument, consider two cities that are differently specialized in high-technology activities in 2001. As high-technology employment grows in all other locations in the country, the city with a deeper initial tech specialization will experience proportionately more growth in 'expected' tech employment. Assuming that a nontrivial proportion of the drivers of local high-technology employment are not location-specific, this instrument should predict the key independent variable of interest sufficiently strongly. And by using purely non-local changes, we argue that Equation 2 will not capture the influence of location-specific shocks that might otherwise generate biased estimates.

Nonetheless, shift-share instruments can be ineffective at identifying short-run causal effects when levels (in this case, of tech employment) are relatively stable over time (Jaeger et al., 2018). Since this is potentially an issue in our context, we consider a second class of instruments that leverage historical patent information. Based on underlying data from Petralia et al., (2016), we generate city-specific measures of the total number of patents between 1836 and 1900 divided by the population in thousands in the nearest Decennial Census (1850 to 1900). Our logic for this measure is that deep historical innovations might predict current levels of frontier technological activity, but are not likely to otherwise shape nontradable real wages. Exploration of these measures shows patterns of cities that only weakly resemble today's larger, more expensive, and famously tech-centric regional economies; interspersed with Seattle and Denver are Duluth WI, Rockford IL, and Rochester NY. A city's level of $19^{\text {th }}$ century patents per thousand is only weakly correlated with both the share of its workers with at least 4 years of college in $2015(r=0.28)$, and median rents $(r=0.26)$. Since our patent instruments are not dynamic over our study period, this instrument must be used in pooled cross sections. Consequently, for these to be informative an additional assumption to be satisfied is that cross- 
sectional and panel estimates are sufficiently comparable.

To investigate our third hypothesis, testing whether tech workers have different consumption patterns, we adapt Equation 1 to consider disaggregated subsectors of local nontradables. We adopt two methods. First, we exploit wage variation between subsectors, using Powell's (2016) quantile estimator with nonadditive fixed effects. Unlike a typical regression, which measures the relationship of interest for nontradable industries at the mean real wage, this procedure allows us to report results for industries at different quantiles of the conditional distribution of real wages across nontradables, while maintaining the benefits of within-CBSA variation in order to eliminate bias from stationary unobserved heterogeneity. Second, we consider how the relationship of interest might vary due to differences in the task content of each nontradable sector. The estimating equation, which includes a linear interaction term between tech employment and task intensity, is as follows:

$$
\ln \left(R W_{c t}^{N T_{i}}\right)=\beta_{0}+\beta_{1} \ln \left(E_{c t}^{T}\right)+\beta_{2}\left(\ln \left(E_{c t}^{T}\right) * K_{x}^{N T_{i}}\right)+\gamma X_{c t}^{\prime}+\mu_{c}+\eta_{t}+v_{c t}
$$

where $N T_{i}$ indexes among subsets of nontradable industries and $K_{x}$ describes a measure of the intensity with which detailed industry $i$ requires task type $x$. To the extent that $\beta_{2}$ is statistically significant, it suggests that the relationship between tech employment and real wages in a particular nontradable sector depends on that sector's task content.

\section{DATA AND MEASUREMENT}

Our primary data comes from the QCEW. QCEW is built from State-submitted Unemployment Insurance (UI) records, which are then linked in order to provide a time series of employment and wages. Since QCEW provides information on the universe of workers covered by State UI programs, as well as Federal employees, its coverage is relatively comprehensive, capturing more than 90 percent of workers in the country. Compared to alternative data sources, QCEW offers additional advantages. One is that, unlike public-use samples of the Decennial Census and American Community Survey, the data completely identify local areas. This means estimates relying on this data ought to be considerably more reliable. Furthermore, since the data are not 
self-reported, they ought to be higher quality than those found in population Census data.

For a given industry and location, the level of coverage in QCEW is determined by confidentiality policy, which seeks to ensure that reported data cannot be used to identify information on firms and individuals. Confidentiality issues arise in jurisdictions with a small number of employers in a given industrial classification. Since we focus on 4-digit NAICS sectors, and relatively densely populated metropolitan regions, our dataset covers in excess of $90 \%$ of the population of total employment in our industries of interest. Although QCEW data are available from 1975 to the present, we confine our analysis to the period 2001-2015, since annual data for certain control variables is missing prior to 2000 .

The scale of interest in this study is the metropolitan regional scale, defined in terms of economic rather than administrative integration. We mainly use definitions for metropolitan Core-Based Statistical Areas (CBSAs), put forth by the Office of Management and Budget (OMB). A metropolitan CBSA is an area containing at least one core urban center with at least 50,000 residents around which are arrayed adjacent communities that are strongly economically and socially integrated to the core. As we explain below, in some models we use a broader regional definition, Combined Statistical Areas (CSAs), which combine adjacent (and meaningfully integrated) metro- and micropolitan CBSAs. Defining the region more broadly limits the detail of the data we can employ in our statistical analysis, but it does help us to avoid potential omitted variable bias, which might occur by excluding workers who may commute to a job from outside of a given CBSA.

\subsection{Distinguishing Tradable and Nontradable Industries}

In order to capture the effects of tradable high-technology employment on the wages of workers in nontradable sectors, we must first distinguish tradable from nontradable industries. One key distinction between the two is their spatial presence. Every town needs dry cleaners and offices

of general practitioners. By contrast, the manufacture of car engines could occur in a very limited number of locales and still satisfy a much wider geographic scope of demand. This intuition has been operationalized as a means of identifying the distinction between tradable and nontradable activities. Following common practice (ie Krugman, 1991; Jensen and Kletzer, 2010, Eliasson et 
al., 2012; Spence and Hlatshwayo, 2012), we measure the level of geographical concentration of each industry using a locational Gini coefficient, given by the following formula:

$$
G_{j}=\sum_{c}\left[E_{c} / E_{U S}-E_{c, j} / E_{U S, j}\right]^{2}
$$

where $E$ equals the level of employment in city $c$ for a given industry $j$. Based on this index, an industry which is geographically dispersed would have a Gini coefficient closer to 0 , whereas one more concentrated would have a value closer to $1 .^{2}$ We estimate Gini coefficients using 4digit NAICS industries, using industry employment data from $2015 .{ }^{34}$ The median level of industry concentration in 2015 is of 0.015 . At the tails, Ginis effectively distinguish tradables from nontradables. As one might expect, however, in the middle these distinctions are less clear. To maximize the validity of our categorization scheme, we manually examine the ranking of industries and categorize industries in the middle whose Gini values do not correspond to expectations regarding tradability. ${ }^{5}$

\subsection{Identifying High-Technology Industries}

To identify high-technology tradables, we adopt a framework proposed by Hecker (2005) that implements guidance from the BLS. The BLS approach considers both input and output dimensions, capturing the intensity of scientific, technical and engineering occupations; R\&D employment; advanced-technology products; and the use of high-technology production methods. We use the strictest of three thresholds defined by Hecker (2005). Under this scheme, tech industries are those in which technology-oriented occupations are present at five times the overall economy-wide average - at least 24.7 percent of total industry employment. ${ }^{6}$

\footnotetext{
${ }^{2}$ As with Jensen and Kletzer (2010), we opt not to adjust measures for the possibility that concentration reflects the presence of a very small number of large plants. Because our interest is in measuring tradability, not agglomeration, concentration in any form is equally relevant.

${ }^{3}$ Comparing Ginis produced for 2015 to those built using data from 2002, we confirm that our results are not driven by the year selected.

${ }^{4}$ We exclude workers in NAICS 92 (Public Administration)

${ }^{5}$ Fuller details of the approach are found in the data appendix at the end of this paper.

${ }^{6}$ Our definition contrasts with somewhat that taken of some closely related studies. For instance, Lee and Rodriguez-Pose (2016) include all three levels described by Hecker (2005), and is thus much more inclusive. This looser threshold includes many manufacturing industries that may involve technological products and processes, but that host workers less engaged in high-wage nonroutine work. Average wage levels are distinctly higher in our Level
} 


\subsection{Measuring Real Wages}

Since living costs vary strongly across regions, nominal incomes as well as incomes deflated using a national consumer price index (CPI) may fail to measure inter-regional differences in economic welfare. Our local CPI measure combines location-specific rents information with national non-housing prices. To measure housing prices, for each county we use HUD data to calculate the average of $50^{\text {th }}$ percentile rents for two- and three-bedroom dwellings, which we sum to the CBSA level weighting by population. Non-housing components are drawn from the $\mathrm{CPI}-\mathrm{U}$, as are annual measures of component weights. Local CPI is calculated as follows:

$$
L C P I_{c, t}=w_{t}^{H}\left(\text { Housing }_{c, t}\right)+w_{t}^{N H}(\text { Nonhousing })
$$

where $w$ measures the relative importance in year $t$ by the CPI program to either housing $(\mathrm{H})$ or nonhousing $(\mathrm{NH})$ components of the CPI-U. ${ }^{7}$ We use our annual LCPI measures as deflators for QCEW-derived annual incomes for workers in nontradable sectors. Hence, we arrive at their real wages as follows:

$$
R W_{c, t}^{N T}={ }^{N W_{c, t}^{N T}} / L C P I_{c, t}
$$

\subsection{Capturing task intensity}

We capture differences between disaggregated components of local nontradable activities in two ways. First, we consider industry-specific variation in average wages. Second, we use data describing how industries vary in terms of their occupational makeup, and how different

\footnotetext{
1 industries than Levels 2 and 3. We believe our stricter threshold is more appropriate given the underlying theory we seek to test. On the other hand, we are more, or differently inclusive than Moretti (2010), who considers only components of high-tech industries that involve manufacturing activities, ignoring design, data processing and other industries that form an important component of contemporary high-technology activity in the U.S. A list of industries classified as high-technology is provided in the Data Appendix.

${ }^{7}$ Historical relative component weights of the CPI-U can be obtained from the BLS, using December as the reference month in each year.
} 
occupations require different kinds of tasks. Industry-specific data on national occupational structure comes from BLS' Occupational Employment Statistics program. Job-specific task information is drawn from the Department of Labor's O*NET database. From the large battery of job characteristics available from O*NET, we select four of particular interest: creativity, originality, innovation, and schooling requirements. We use $\mathrm{O}^{*} \mathrm{NET}$ information quantifying the occupation-specific importance of each characteristic. Combining this with the OES data, for each characteristic, we calculate the weighted sum of all occupations' scores, where the weight is the share of total industry employment represented by a particular occupation.

\subsection{Main control variables}

We include two dynamic control variables in all specifications. First, we measure the year- and region-specific unemployment rate, expressed as a percentage, using data from the BLS Local Area Unemployment Program. High levels of unemployment could put downward pressure on nominal wages as well as on the housing market. Second, using data from one percent extracts from the American Community Survey, drawn from IPUMS (Ruggles et al, 2015), we measure the share of non-institutional, actively employed workers over the age of 25 with at least a 4-year degree. Because metro-level identifiers in the ACS are not available between 2001 and 2004, we use geometric interpolation to impute educational attainment during these years. Though the existing literature is unclear on whether educational spillovers of the type reported in studies like Rauch (1993) and Moretti (2004) extend to workers in nontradable sectors, we include this measure to ensure that measures of the relationship between tech employment and nontradable wages are not driven instead by productivity spillovers from the presence of highly-educated workers. In certain models, we also include the minimum wage prevalent in each metro area, which might also influence the wages of nontradable workers. In the U.S., the minimum wage is mostly determined by either the federal or state governments - with many states legislating for minimum wage levels beyond the federal figure. Minimum wage data are available from the U.S. Department of Labor. While some local governments set minimum wage levels higher than the state or federal figure, local action is highly infrequent, and since CBSAs are our unit of analysis, we use the federal or state level that is relevant to the majority of communities within a given metro area. 


\section{RESULTS}

\subsection{Descriptive Results}

Table 2 presents descriptive statistics for key variables in the 349 metropolitan CBSAs that constitute the primary analytical sample, with values presented for the year 2015 . The average urban worker in nontradable activities earns around $\$ 36,000$ in nominal terms, and $\$ 26,000$ in real terms. The average metro CBSA hosts around 14,000 workers in tradable high-technology activities, and 18,000 jobs in non-high-technology tradables. Over the period, which includes the Great Recession, local unemployment rates averaged less than six percent, and about 17 percent of adult workers had attended at least four years of college.

Table 2. Summary Statistics for Key Variables of Interest in Metropolitan CBSAs in 2015

\begin{tabular}{lcc}
\hline Variable & Mean & $\begin{array}{c}\text { Standard } \\
\text { Deviation }\end{array}$ \\
\hline Nominal wages for workers in nontradable sectors (\$) & 6,278 \\
Real wages for workers in nontradable sectors (\$) & 35,842 & 3,706 \\
High-technology tradable employment & 25,959 & 48,658 \\
Non-high-technology tradable employment & 16,284 & 61,773 \\
Unemployment rate (\%) & 21,512 & 1.96 \\
Workers over 25 years old with at least 4 years of College (\%) & 5.49 & 4.62 \\
Median Rent for 2 and 3 Bedroom Dwelling & 17.16 & 263 \\
Minimum wage & 1,050 & 0.71 \\
\hline Note: Authors' calculations based on data described in Section 4. All variables measured over 349 metropolitan CBSAs.
\end{tabular}

The measure of dispersion indicates considerable variation across cities, especially in terms of employment in tradable activities. This makes sense given the relatively heterogeneous nature of the metro CBSA category: although it has a minimum population threshold, it contains cities like New York and Los Angeles, with populations well over ten million inhabitants, as well as Hinesville, Georgia, with just over 80,000 residents. Similarly, metropolitan areas hosting the largest agglomerations of high-technology activity, like San Jose, Los Angeles, and New York employ an order of magnitude more workers in such activities than the average city.

Crucially for our purposes, over our study period there is also meaningful temporal variation within cities. The median city expands its high-technology employment base by just over ten percent, and the interquartile range spans seven percent to an increase of just over 50 percent. More concretely, the average city added 1,000 new tech jobs, while a few larger metropolitan 
areas, notably Seattle, San Francisco and Houston, added tens of thousands of new tech jobs, and Los Angeles, Miami and Philadelphia fall considerably short of their boom-era peaks in the early 2000s.

\subsection{What is the relationship between local high-technology employment and the real wages of} workers in nontradable sectors?

We now turn to estimating the main relationship of interest. The analysis is chiefly conducted on a panel of cities, using two estimators: heteroscedasticity-robust ordinary least squares (OLS), and subsequently, robust two-stage least squares (2SLS). In each model, city fixed effects account for stationary unobserved heterogeneity among regional economies. ${ }^{8}$ Year fixed effects are included to capture unmeasured shocks that are uniform across cities, but which vary over time. The independent variable of interest is local high-technology employment. Because we are interested in capturing the effects of relatively permanent changes in this variable, throughout our analysis we use 3-year moving averages of tech employment, centered on the current year. Where possible, we include measures of unemployment and the proportion of workers with at least four years of college education as controls. Both the dependent variable and key independent variable are measured in log form, minimizing scale issues. To facilitate the use of the historical patenting instrument, in certain models we pool observations across years; in such cases city fixed effects are not included.

The first hypothesis to be tested states that changes in local high-technology employment raise the real wages of workers in nontradable sectors. Evidence is shown in Table 3. To begin, in Model 1 we describe the relationship between tech employment and raw, nominal wages. The coefficient on tech employment is positive and statistically significant at a 1 percent. In all subsequent models, the dependent variable is real wages for workers in nontradables. Model 2 presents estimates in which tech employment is the only predictor. The coefficient on tech

\footnotetext{
${ }^{8}$ While a Hausman specification test indicated that a random effects model generated more efficient estimates of the relationship of interest, actual differences between each estimated coefficient in fixed versus random effects models was substantively negligible. This together with the strong need to account for the potential effects of unobserved heterogeneity push for the fixed effects approach described in Equation 1.
} 
employment remains positive and statistically significant at a 1 percent level. Although the point estimate is actually slightly larger than that for nominal wages, their 95 percent confidence intervals overlap. Model 3 presents our baseline estimate of the relationship of interest. As in the prior models, the coefficient on tech employment remains positive and statistically significant. Its magnitude suggests that a ten percent increase in local high-technology employment is associated with a little over a 0.1 percent increase in the annual real wages of workers in nontradable sectors. In other words, though significant in statistical terms, our baseline estimate reveals a substantively modest relationship between tech employment and nontradable real wages. In terms of its relationship to estimates for nominal wages, as above there is a large degree of overlap between the two confidence intervals, suggesting that price changes in local living costs do not play a decisive role in shaping the real wages of workers in nontradables across the full range of metropolitan CBSAs. Coefficients on control variables in the baseline model are broadly as expected, with the lack of significance of the college share variable suggesting there is not a clear social return to education spilling over to workers in nontradables. Based on the possibility that average nontradable wages may be affected by changes in the minimum wage, Model 4 adds a measure of local minimum wages. These do not enter significantly in this model, and the main coefficient of interest remains unchanged.

In Model 5 we test the possibility that our estimate of the relationship of interest is driven by Baumol's cost disease, instead of by derived-demand explanations that form the primary basis of the hypotheses. To do so, we drop those nontradable activities that have been mainly associated with cost disease measurement: those involved in education, the arts and health care. ${ }^{9}$ To the extent that results excluding these sectors remain consistent, it suggests that cost-disease mechanisms are not the primary drivers of the links between tech and nontradable wages. Although, counter-intuitively, the coefficient on tech employment in this model is somewhat larger than that generated for the full complement of nontradables; it remains positive, significant, and substantively small. These results support the derived-demand channel.

\footnotetext{
${ }^{9}$ Specifically, we disinclude all 4-digit NAICS sectors within NAICS 61 (Education services), and 62 (Health care and social assistance), as well as 7111 (Performing arts companies), 7115 (Independent artists, writers, and performers), and 8122 (Death care services).
} 
Table 3. The relationship between high-technology employment and the wages of workers in nontradable industries, 2001-2015

\begin{tabular}{|c|c|c|c|c|c|c|c|c|c|}
\hline & \multicolumn{7}{|c|}{ Panel 2001-2015 } & \multicolumn{2}{|c|}{ Pooled 2001-2015 } \\
\hline & $\begin{array}{l}\text { Nominal } \\
\text { Wages } \\
(1)\end{array}$ & $\begin{array}{c}\text { No } \\
\text { controls } \\
(2)\end{array}$ & $\begin{array}{l}\text { Baseline } \\
\text { (3) }\end{array}$ & $\begin{array}{c}\text { Baseline + } \\
\text { Min Wage } \\
\text { (4) }\end{array}$ & $\begin{array}{l}\text { No Baumol } \\
\text { Sectors } \\
(5)\end{array}$ & $\begin{array}{l}\text { CSAs \& } \\
\text { CBSAs } \\
(6)\end{array}$ & $\begin{array}{l}\text { 2SLS } \\
\text { FE } \\
(7)\end{array}$ & $\begin{array}{l}\text { OLS } \\
(8)\end{array}$ & $\begin{array}{l}\text { 2SLS } \\
(9)\end{array}$ \\
\hline Tech tradable employment & $\begin{array}{c}0.011 * * * \\
(0.003)\end{array}$ & $\begin{array}{c}0.017 * * * \\
(0.003)\end{array}$ & $\begin{array}{c}0.013 * * * \\
(0.003)\end{array}$ & $\begin{array}{c}0.013 * * * \\
(0.003)\end{array}$ & $\begin{array}{c}0.024 * * * \\
(0.003)\end{array}$ & $\begin{array}{c}0.013 * * \\
(0.005)\end{array}$ & $\begin{array}{c}0.041 * * \\
(0.015)\end{array}$ & $\begin{array}{c}0.050 * * * \\
(0.001)\end{array}$ & $\begin{array}{c}0.078^{* * *} \\
(0.003)\end{array}$ \\
\hline Unemployment rate & $\begin{array}{c}-0.009 * * * \\
(0.001)\end{array}$ & & $\begin{array}{c}-0.013 * * * \\
(0.001)\end{array}$ & $\begin{array}{c}-0.013 * * * \\
(0.001)\end{array}$ & $\begin{array}{c}-0.016^{* * *} \\
(0.001)\end{array}$ & & $\begin{array}{c}-0.013 * * * \\
(0.001)\end{array}$ & $\begin{array}{c}-0.015 * * * \\
(0.001)\end{array}$ & $\begin{array}{c}-0.019 * * * \\
(0.001)\end{array}$ \\
\hline $\begin{array}{l}\text { College share } \\
\text { Minimum wage }\end{array}$ & $\begin{array}{c}0.000 \\
(0.001)\end{array}$ & & $\begin{array}{c}0.000 \\
(0.001)\end{array}$ & $\begin{array}{c}0.000 \\
(0.001) \\
0.002 \\
(0.002)\end{array}$ & $\begin{array}{c}0.000 \\
(0.001)\end{array}$ & & $\begin{array}{l}-0.000 \\
(0.001)\end{array}$ & $\begin{array}{c}-0.011 * * * \\
(0.001)\end{array}$ & $\begin{array}{c}-0.018 * * * \\
(0.001)\end{array}$ \\
\hline
\end{tabular}

First Stage Results

Expected tech empl.

Patents (per thousand pop)

$0.013 * * *$

(0.002)

City effects

Kleibergen-Paap rk Wald F

R-squared

$\mathrm{N}$ 4,108

$\begin{array}{lll}0.976 & 0.928 & 0.931 \\ 4,108 & 4,108 & 4,108\end{array}$

\begin{tabular}{lll}
0.931 & 0.931 & 0.943 \\
4,108 & 4,108 & 4,108 \\
\hline
\end{tabular}

0.884
3,207

metropolitan CBSAs except in Model 4, which metropolitan CBSAs except in Model 4, which replaces CBSAs with CSAs where they exist. Dependent variable in all models except Mode1 1 is real wages for described in Section 4. 
In Model 6, we consider an alternative geographical unit of analysis. On the intuition that workers in nontradable sectors might be priced out of metropolitan areas into adjacent, more peripheral and presumably more affordable 'micropolitan' CBSAs, we re-estimate our baseline model defining regional economies according to OMB definitions for Combined Statistical Areas (CSAs), where available, and otherwise using metropolitan CBSAs. A perfect analogue of the baseline model is not possible in this sample, given the inability to measure control variables in micropolitan areas. Nonetheless, we can compare estimates for tech employment between this model and a CBSA-only model that is similarly parsimonious (Model 2). These models produce results that closely resemble one another. In short, our findings are robust to an alternative geography where the borders of local labor markets are drawn more extensively.

To account for potential bias from unobserved shocks to localities, Model 7 instruments for hightech employment using the shift-share measure described in Equation 2, using the 2SLS estimator with heteroscedasticity-robust standard errors. The instrument passes tests of underand weak-identification. Second-stage results closely resemble those reported for the baseline model (Model 3), although the IV-derived point estimate and confidence interval are larger. The overall consistency across IV and OLS results provides evidence to support the notion that localized unobserved shocks are not driving the relationship of interest. Since the instrument used in Model 3 strips away location-specific unobserved factors, we are left with an estimate whose causal significance is clearer: it suggests that expansions in local tech employment exert an independent, positive effect on the real wages of workers in nontradable sectors.

To further strengthen confidence in the causal nature of the relationship, we turn to our instrument measuring CBSA-specific $19^{\text {th }}$ century patenting activity. Whereas the shift-share instrument aims to provide exogenous variation by abstracting away from the individual location, our aim with the patent instrument is to find place-specific variation that is plausibly uncorrelated with unobserved factors that explain real wages over the study period - a minimum of one hundred and one years later. As described above, one limitation of this instrument is that it is not dynamic. Hence, we must first determine the extent to which we find generally 
consistent results across models with and without locational fixed effects, the former of which depend on our exploitation of the panel structure of our data. Model 8 estimates a version of Equation 1 in which information is pooled across all years of the data, and in which city and year fixed effects are not included. While the coefficient on tech employment is somewhat larger in models in which these fixed effects are present, results remain broadly consistent. This encourages our use of the patent instrument. Model 9 present 2SLS estimates, instrumenting for tech employment with total CBSA patents between 1836 and 1900, scaled per thousand population. The instrument passes tests of under- and weak-identification, and second-stage results hew reasonably closely to those generated in the uninstrumented model. These results broadly support the findings thus far, suggesting that the estimates are not biased by unobserved location-specific shocks. ${ }^{10}$

\subsection{Is high-technology employment special?}

Next we consider the second hypothesis: the extent to which tech has a unique relationship with nontradable real wages when compared with other tradable activities. In 2015, the average worker in tech activities earned 42 percent more than their counterpart in non-tech tradables. This premium is consistent across the full study period. Consequently, one might expect larger benefits for workers in nontradable sectors flowing from tech as opposed to non-tech tradables. To explore whether this is the case, we include non-tech tradable employment as an additional predictor.

Figure 1. Average marginal effects with 95\% confidence interval of one log point increase in local high-technology employment on log annual real wages of workers in nontradable sectors, 2001-2015

\footnotetext{
${ }^{10}$ We conduct some additional robustness checks not shown in Table 3 . To explore whether results depend on our use of 3-year moving averages for both our dependent variable and our key independent variable, we also estimate models using unadjusted single-year values. These results are materially consistent with those we report in the paper. Given that there are a handful of regions whose levels and growth in tech employment over the study period are quite different from the average, we also explore the robustness of our results to the exclusion of these outliers. We estimate a succession of models in which San Jose, San Francisco, Seattle, Los Angeles, as well as all possible combinations of these regions are removed from the analytical sample. Their inclusion does not fundamentally shape estimates of the relationship of interest.
} 

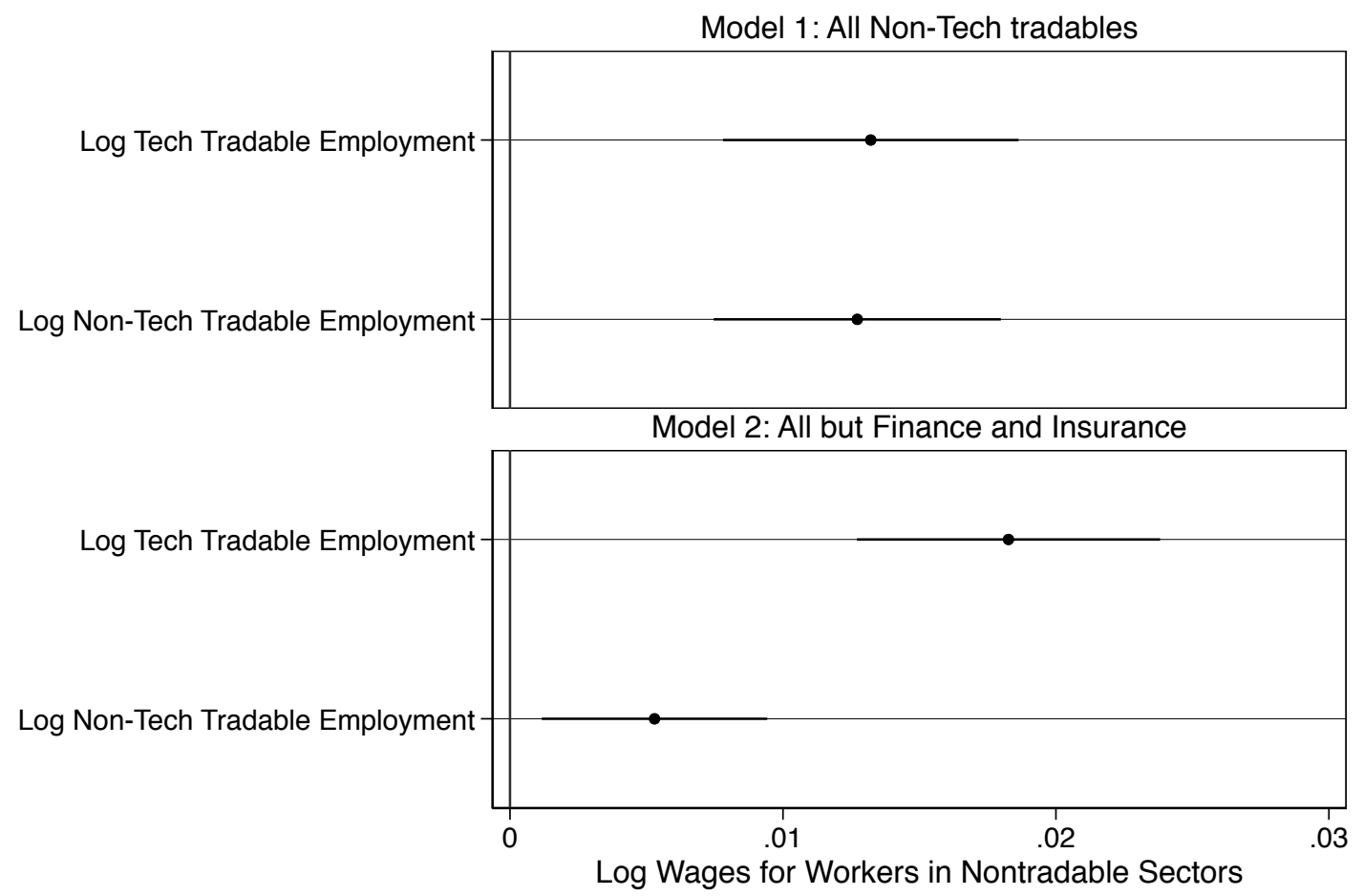

Note: Each model presents coefficient and 95\% confidence interval describing the relationship between high technology employment and the nominal or real wages of workers in nontradable sectors. Models estimated on 2001-2015 panel of metropolitan CBSAs. Each model includes city and year fixed effects, and additionally contains controls for unemployment and the share of workers with at least 4 years of college education. Estimates with CIs that cross the zero mark are not statistically significant at a 5\% level. $\mathrm{N}$ for Models $1 \& 2=4,108$; Full regression results available upon request.

Figure 1 reports coefficients for 'horse-race' style models including both tech and non-tech tradables as predictors. Models include the typical controls, as well as city and year fixed effects. In Model 1, the coefficient on tech employment remains the same as that estimated in the baseline model. However, counter to our intuition, in Model 1 we find statistically indistinguishable coefficients for tech and non-tech tradable employment. On the intuition that this outcome might be driven by small number of very high-paying but nonetheless nontechnological industries - in particular finance and insurance - in Figure 1, Model 2 we measure non-tech tradables without 4-digit industries falling into these categories. ${ }^{11}$ Having done so, the coefficient on tech employment grows larger than that estimated for the restricted group of nontech tradables. While this finding hews closer to expectations, estimates for tech and non-tech

\footnotetext{
${ }^{11}$ Specifically, we disinclude NAICS 5222, 5231, 5232, 5239 and 5259 and put these in our indeterminate category.
} 
employment remain surprisingly similar. Given the average wage gap between tech and non-tech tradables, the lack of a substantial gap in terms of effects on nontradable real wages remains a puzzle.

5.4 Do the effects of tech employment vary according to the task and wage profile of specific subsectors of nontradable activity?

Our third hypothesis is that the links between tech employment and aggregate nontradable real wages may conceal meaningful internal heterogeneity that we may see only by disaggregating each city's bundle of nontradables. Lacking unambiguous theoretical guidance, we consider the idea that tech employment might spur greater growth in demand for nontradable activities that are more highly-remunerated, as well as those intensive in creativity and skill. To explore the possibility that the effect of tech will vary according to the level of wages paid in particular nontradable sectors, we make use of a quantile estimator with nonadditive fixed effects, optimizing with Markov Chain Monte Carlo (MCMC) methods.

Figure 2 presents results across the conditional distribution of nontradable real wages. Point estimates vary between approximately 0.008 (at the fifth and $75^{\text {th }}$ percentiles) to nearly 0.04 . These differences are not large in substantive terms, however a considerable amount of overlap across 95 percent confidence intervals indicates that actual population parameters also do not vary across quantiles. Based on this, we reject the idea that workers in nontradable sectors at different positions in the distribution of real wages reap meaningfully different rewards from growth in local tech employment. 
Figure 2. Marginal effects of high-tech employment on quantile $Q_{T}$ of nontradable wage distribution, 2001-2015.

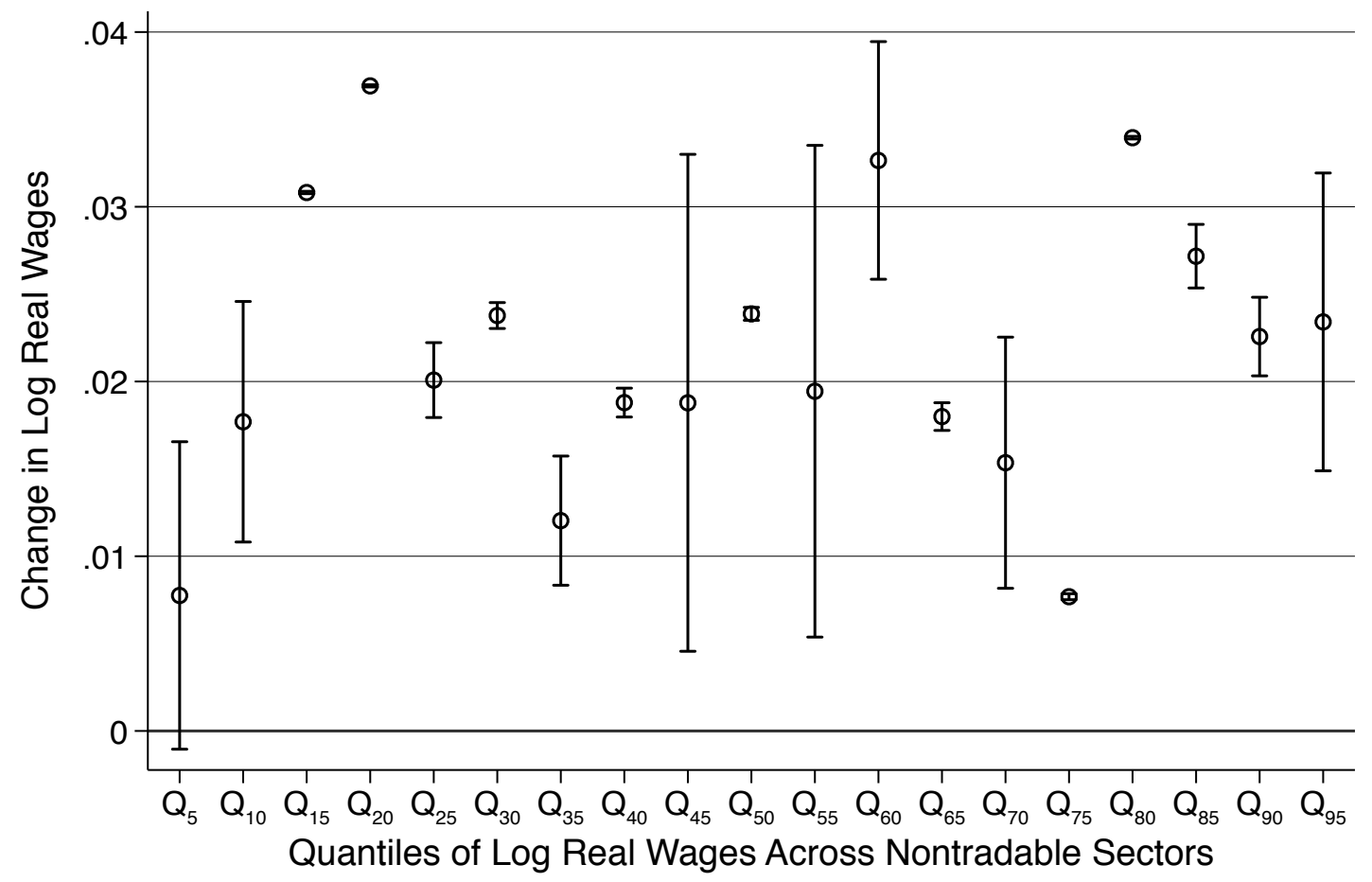

Note: Each quantile shows a point estimate and 95\% confidence interval for high-technology employment at a point in the conditional distribution. Quantiles estimated in separate models, which include education, unemployment, year, and CBSA fixed effects, with robust standard errors. Estimates produced on a panel of 4-digit nontradable sectors in 349 metropolitan CBSAs. Estimates with CIs that cross the zero mark are not statistically significant at a $5 \%$ level. $\mathrm{N}=403,642$; Full regression results available upon request.

Next we examine differences in job characteristics. The idea we wish to explore is that the effects of changes in tech employment on nontradables depends on the job characteristics involved in a particular nontradable industry. Table 4 presents results in which we interact local tech employment with industry-specific measures of creativity, originality, innovativeness, and schooling requirements. Estimates in Table 4 include city and year effects. Standard errors are clustered at the CBSA-level, on the basis that wage-setting ought to be non-independent across sectors within a regional economy. 
Table 4. The relationship between high-technology employment and the real wages of workers in nontradable industries by job characteristics, 2001-2015

\begin{tabular}{|c|c|c|c|c|}
\hline & $\begin{array}{c}\text { Creativity } \\
(1) \\
\end{array}$ & $\begin{array}{l}\text { Originality } \\
(2)\end{array}$ & $\begin{array}{c}\text { Innovativeness } \\
\text { (3) } \\
\end{array}$ & $\begin{array}{c}\text { Schooling Requirements } \\
(4)\end{array}$ \\
\hline Tech Tradable Employment & $\begin{array}{c}0.014 \\
(0.012)\end{array}$ & $\begin{array}{c}0.027 \\
(0.015)\end{array}$ & $\begin{array}{c}0.011 \\
(0.014)\end{array}$ & $\begin{array}{c}-0.011 \\
(0.008)\end{array}$ \\
\hline Tech * Creativity & $\begin{array}{l}-0.006 \\
(0.023)\end{array}$ & & & \\
\hline Tech * Originality & & $\begin{array}{c}-0.043 \\
(0.036)\end{array}$ & & \\
\hline Tech * Innovativeness & & & $\begin{array}{c}0.001 \\
(0.027)\end{array}$ & \\
\hline Tech * Schooling Requirements & & & & $\begin{array}{c}0.086^{* *} \\
(0.028)\end{array}$ \\
\hline Non-tech Tradable Employment & $\begin{array}{l}0.008^{*} \\
(0.004)\end{array}$ & $\begin{array}{l}0.008^{*} \\
(0.004)\end{array}$ & $\begin{array}{l}0.008 * \\
(0.004)\end{array}$ & $\begin{array}{l}0.008^{*} \\
(0.004)\end{array}$ \\
\hline Unemployment Rate & $\begin{array}{c}-0.011 * * * \\
(0.001)\end{array}$ & $\begin{array}{c}-0.011 * * * \\
(0.001)\end{array}$ & $\begin{array}{c}-0.011 * * * \\
(0.001)\end{array}$ & $\begin{array}{c}-0.011 * * * \\
(0.001)\end{array}$ \\
\hline College Share & $\begin{array}{c}-0.000 \\
(0.001)\end{array}$ & $\begin{array}{l}-0.000 \\
(0.001)\end{array}$ & $\begin{array}{l}-0.000 \\
(0.001)\end{array}$ & $\begin{array}{l}-0.000 \\
(0.001)\end{array}$ \\
\hline R-squared & 0.955 & 0.955 & 0.955 & 0.955 \\
\hline $\mathrm{N}$ & 393,504 & 393,504 & 393,504 & 393,504 \\
\hline
\end{tabular}

In Table 4, Models 1-3, the interaction terms between tech and creativity, originality and innovativeness are not significant, indicating that the effect of tech employment do not vary across different levels of these characteristics. Model 4, featuring an interaction with schooling requirements is significant at a five percent level. Figure 3 visualizes the relationship for the $10^{\text {th }}$, $50^{\text {th }}$ and $90^{\text {th }}$ percentiles of schooling requirements. The figure suggests that the rewards from rising tech employment rise with schooling requirements in nontradable industries. Nonetheless, substantive magnitudes remain small, with values indistinguishable from zero for those at the $10^{\text {th }}$ percentile of schooling requirements, ranging to a 0.2 percent increase in real wages in response to a ten percent increase in tech employment in sectors where schooling requirements are at the $90^{\text {th }}$ percentile. To build some confidence that these differentiated results are not explained by cost-disease mechanisms, we re-estimate the schooling interaction for the range of nontradables except for nontradables in education, health care, and the arts, as in Section 5.2. The interaction term remains significant, remains substantively comparable. 
Figure 3. The relationship between high-technology employment and the real wages of workers in nontradable industries by levels of schooling requirements, 2001-2015

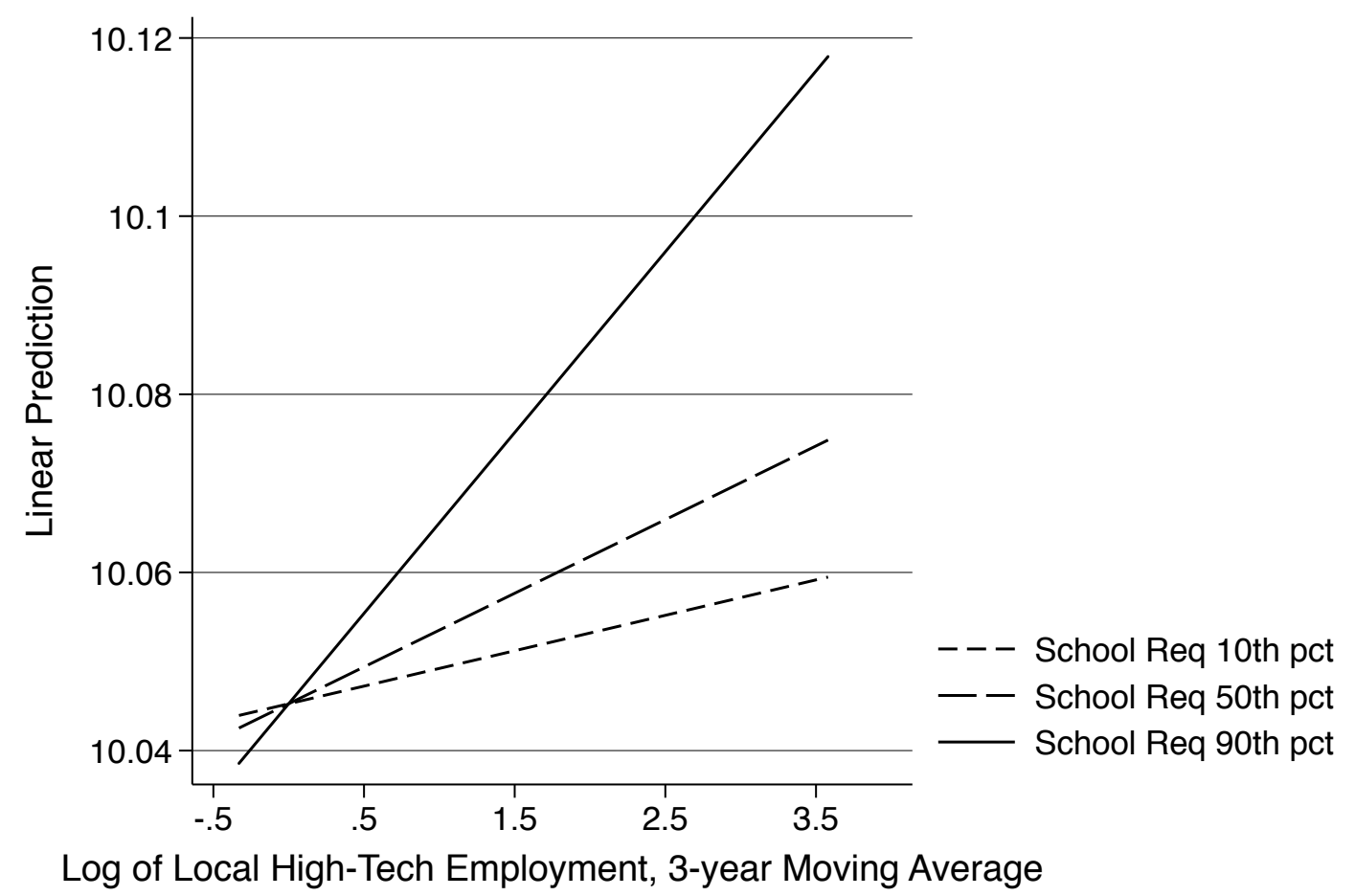

Note: This figure visualizes the relationship described in Table 4, Model 16. Estimates produced using robust standard errors, clustered at CBSA level. College share, unemployment city and year effects included in model. The unit of observation is a CBSA-specific 4-digit nontradable sector. Further variable details described in Section 4.

\section{CONCLUSION}

This paper set out to explore the relationship between local high-technology employment and the real wages of workers in nontradable sectors. Scholars have long considered the direct impacts of high-technology and other kinds of specialization on regional economic performance. Others have examined indirect, wider effects, but this work has largely concentrated on job creation as an outcome, despite recent theory identifying mechanisms through which tradable jobs can affect local nontradable wages. This paper contributes to recent efforts to explore this channel empirically. It does so in several ways, most importantly by considering how employment growth in tech might shape not only nominal wages, but wages adjusted for local living costs. 
Based on the estimation approach, data, and comprehensive coverage, this paper offers the clearest available evidence linking high-technology employment to the economic welfare of workers in nontradables activities. Our results show that, for the average metropolitan area in the United States, growth in tech employment offers statistically significant but substantively modest real wage benefits for workers in nontradables. We find that a ten percent increase in tech employment -the median over our study period - is associated with between a 0.1 and 0.7 percent increase in nontradable real wages. This size of the relationship we document does not strongly depend on the distinction between nominal and real wages. One way to interpret this finding is that the interactions in iconic tech hubs between tech and strongly inelastic housing markets is not the universal, or even majority urban tech experience. Moreover, we find that the relationship between tech employment and nontradable real wages is not unique; despite differences in average wages it differs only moderately from that measured for not-tech tradables. Finally, we find that changes in tech employment have fairly consistent real wage effects across the spectrum of local nontradable work. We identify scant substantive variation across wage quantiles. Moreover, though we find that real wage gains rise modestly with schooling requirements, they are not larger in nontradable industries that more intensively require creativity, originality or innovativeness.

A few limitations are worth discussing. One factor limiting our ability to measure the relationship of interest is the granularity of available industry codes. To give an example, restaurants are grouped into a single 4-digit industry, called 'Restaurants and other eating places'. To the extent that tech workers favor particular fine dining over fast food, researchers face few options. Data on occupations may offer greater promise, but even here granularity is an issue, especially if one also requires time series and detailed geography. The ideal scenario would be one which permitted analysts to follow individuals across time, with detailed information about their industry, occupation, and wages. One important but unanswered question such data could address is the distribution of gains among migrants and locals. At this time such data are not available for the U.S. A further caveat has to do with our instrumental variables strategy. The evidence we report should generate some confidence that the links between tech employment and nontradable wages are causal, but caution is warranted, given the possibility that our instruments are not fully orthogonal to unobserved factors. One promising 
complementary approach would be to leverage natural experiments. Major shocks to tech employment, of the kind represented by Amazon's HQ2, for instance, could be matched to cities that bid unsuccessfully in order to glean treatment effects. Finally, the paper leaves unanswered why it is that tech and non-tech tradables generate broadly comparable real wage effects, despite differences in average salaries. Future research should pursue this question further.

It is also worth briefly identifying possible effects that lie outside the boundaries of the present study. There remain other channels through which tech employment might improve the welfare of other workers. Perhaps chief among these is taxation, of individuals, business profits and property. Tax collected from these sources can improve public finances at multiple scales, and has the potential to generate greater provision of public goods, like schools, roads, hospitals. Future research should carefully examine this relationship. At the same time, rising tech employment might still generate real negative externalities that remain unmeasured in our study, for instance associated with being displaced from one's longstanding community.

Finally, to the extent that wider prosperity is an important desired outcome of tech-focused industry-attraction policies, this study offers cautionary evidence. When weighed against large subsidies offered to high-technology firms, the modest effects identified in this study suggest that such policies are misguided. 


\section{References:}

Autor, D., Katz, L. F., \& Kearney, M. S. (2006). The Polarization of the US Labor

Market. American Economic Review, 96(2), 189-194.

Bartik, T. J. (1991) Who Benefits from State and Local Economic Development Policies? Kalamazoo: Upjohn Press.

Baumol, W. J. (1967). Macroeconomics of unbalanced growth: the anatomy of urban crisis. The American economic review, 415-426.

Block, F., \& Keller, M. R. (2009). Where do innovations come from? Transformations in the US economy, 1970-2006. Socio-Economic Review, 7(3), 459-483.

Breau, S., Kogler, D. F. and Bolton, K. C. (2014), On the Relationship between Innovation and Wage Inequality: New Evidence from Canadian Cities. Economic Geography, 90, 351-373.

Bureau of Economic Analysis (2016) Regional Economic Accounts: Methodologies. Real Personal Income and Regional Price Parities. Retrieved June 27, 2017 from: https://www.bea.gov/regional/methods.cfm

CNN Money (2018) What these states learned about wooing companies with big tax breaks. Retrieved February 19, 2018 from: http://money.cnn.com/2018/02/13/news/economy/amazonhq2-tax-incentives/index.html

Centner, R. (2008). Places of Privileged Consumption Practices: Spatial Capital, the Dot- Com Habitus, and San Francisco's Internet Boom. City \& Community, 7(3), 193-223.

Chatterji, A., Glaeser, E., \& Kerr, W. (2014). Clusters of entrepreneurship and innovation. Innovation Policy and the Economy, 14(1), 129-166.

Clark, N. G. (1972). Science, technology and regional economic development. Research Policy, 1(3), 297-319.

Daly, M. C., Hobijn, B., \& Pyle, B. (2016). What's Up with Wage Growth? FRBSF Economic Letter, 7.

De Blasio, G., \& Menon, C. (2011). Local effects of manufacturing employment growth in Italy. Giornale degli Economisti e Annali di Economia, 101-112.

Diamond, R. (2016). The determinants and welfare implications of US workers' diverging location choices by skill: 1980-2000. The American Economic Review, 106(3), 479-524.

Drennan, M. P., Tobier, E., \& Lewis, J. (1996). The interruption of income convergence and income growth in large cities in the 1980s. Urban Studies, 33(1), 63-82.

Duranton, G. (2011). California dreamin': The feeble case for cluster policies. Review of Economic Analysis, 3(1), 3-45. 
Echeverri-Carroll, E., \& Ayala, S. G. (2009). Wage differentials and the spatial concentration of high-technology industries. Papers in Regional Science, 88(3), 623-641.

Eliasson, K., Hansson, P., \& Lindvert, M. (2012). Jobs and exposure to international trade within the service sector in Sweden. The World Economy, 35(5), 578-608.

Faggio, G., \& Overman, H. (2014). The effect of public sector employment on local labour markets. Journal of Urban Economics, 79, 91-107.

Fallah, B., Partridge, M. D., \& Rickman, D. S. (2014). Geography and High-Tech Employment Growth in US Counties. Journal of Economic Geography, 14(4), 683-720.

Federal Committee on Statistical Methodology (2005) Report on Statistical Disclosure Limitation Methodology. Statistical Policy Working Paper 22. Office of Management and Budget. Washington DC.

Feldman, M., Hadjimichael, T., Lanahan, L., \& Kemeny, T. (2016). The logic of economic development: a definition and model for investment. Environment and Planning C: Government and Policy, 34(1), 5-21.

Fleming, D. A., \& Measham, T. G. (2014). Local job multipliers of mining. Resources Policy, 41, 9-15.

Frocrain, P., \& Giraud, P. N. (2017). The evolution of tradable and non-tradable employment: evidence from France. Institute interdisciplinaire de l'innovation, Working Paper 17-CER-04

Fowler, C. S., \& Kleit, R. G. (2014). The effects of industrial clusters on the poverty rate. Economic Geography, 90(2), 129-154.

Galbraith, J.K. and Hale, T. (2004) Income distribution and the information technology bubble. University of Texas Inequality Project, Working Paper 27.

Ganong, P., and Shoag, D. (2017). Why has regional income convergence in the US declined? NBER Working Paper No. 23609.

Giannone, E. (2017). Skilled-Biased Technical Change and Regional Convergence. University of Chicago Working Paper, available at: http://home.uchicago.edu/ elisagiannone/files/JMP ElisaG.pdf

Glaeser, E., Kallal, H., Scheinkman, J., Shleifer, A. (1992) Growth in cities. Journal of Political Economy, 100 (1992), pp. 1126-1152

Gyourko, J., Saiz, A., \& Summers, A (2008) A New Measure of the Local Regulatory Environment for Housing Markets: Regulatory Index. Urban Studies, 45:693-729. 
Henig, J. R. 1980. Gentrification within cities: A comparative analysis. Social Science Quarterly, 61(3): 639-652.

Howells, J. (2005). Innovation and regional economic development: A matter of perspective? Research policy, 34(8), 1220-1234.

Hyra, D. (2015). The back-to-the-city movement: Neighbourhood redevelopment and processes of political and cultural displacement. Urban Studies, 52(10), 1753-1773.

Jensen, J. B., \& Kletzer, L. G. (2010). Measuring tradable services and the task content of offshorable services jobs. In Labor in the new economy (pp. 309-335). University of Chicago Press.

Heckler, D. E. (2005). High-technology employment: a NAICS-based update. Monthly Labor Review. 128, 57.

Kemeny, T., \& Storper, M. (2015). Is specialization good for regional economic development? Regional Studies, 49(6), 1003-1018.

Krugman, P. (1991) Geography and Trade. MIT Press, Cambridge, MA.

North, D. C. (1955). Location theory and regional economic growth. Journal of political economy, 63(3), 243-258.

Malecki, E.J. (1981) Science, technology, and regional economic development: Review and prospects. Research Policy 10(4), 312-334.

Mashable (2017) Blue Bottle's investment success owes much to the personal tastes of Silicon Valley investors. Retrieved February 19, 2018 from: https://mashable.com/2017/09/16/bluebottle-tech-elite-fancy-coffee/\#.GgTV89Npiq9

Molloy, R., Smith, C. L., \& Wozniak, A. (2011). Internal migration in the United States. The Journal of Economic Perspectives, 25(3), 173-196.

Moretti, E. (2004). Estimating the social return to higher education: evidence from longitudinal and repeated cross-sectional data. Journal of econometrics, 121(1), 175-212.

Moretti, E. (2010) Local Multipliers. American Economic Review: Papers \& Proceedings 100, 373-377

Moretti, E. (2012). The new geography of jobs. Houghton Mifflin Harcourt.

Moretti, E. (2013). Real wage inequality. American Economic Journal: Applied Economics, 5(1), $65-103$.

Moretti, E., \& Thulin, P. (2013). Local multipliers and human capital in the United States and Sweden. Industrial and Corporate Change, 22(1), 339-362. 
National Urban Coalition. 1978. Displacement: City Neighborhoods in Transition. National Urban Coalition, Washington, D.C.

New York Times (2017) Where Silicon Valley Is Going to Get in Touch With Its Soul.

Retrieved on February 19, 2018 from: https://www.nytimes.com/2017/12/04/technology/siliconvalley-esalen-institute.html

Petralia, S., Balland, P. A., \& Rigby, D. L. (2016). Unveiling the geography of historical patents in the United States from 1836 to 1975 . Scientific data, 3, 160074.

Poole, R., Ptacek, F., and Verbrugge, R. (2005) Treatment of Owner-Occupied Housing in the CPI. Office of Prices and Living Conditions, Bureau of Labor Statistics, Washington DC.

Porter, M. (2003). The economic performance of regions. Regional studies, 37(6-7), 549-578.

Powell, David (2016) Quantile Regression with Nonadditive Fixed Effects. Mimeo.

Rauch, J. E. (1993). Productivity gains from geographic concentration of human capital: evidence from the cities. Journal of urban economics, 34(3), 380-400.

Richardson, H. W. (1985). Input- Output and Economic Base Multipliers: Looking Backward and Forward. Journal of Regional science, 25(4), 607-661.

Steven Ruggles, Katie Genadek, Ronald Goeken, Josiah Grover, and Matthew Sobek. Integrated Public Use Microdata Series: Version 6.0 [dataset]. Minneapolis: University of Minnesota, 2015. http://doi.org/10.18128/D010.V6.0.

Rushkoff, D. (2017). Throwing rocks at the Google bus: how growth became the enemy of prosperity. Penguin.

Saiz, A. (2010) The Geographic Determinants of Housing Supply. Quarterly Journal of Economics, 125(3): 1253-1296

Schafran, A. (2013). Origins of an urban crisis: The restructuring of the San Francisco Bay area and the geography of foreclosure. International Journal of Urban and Regional Research, 37(2), 663-688.

Scott, A. J., \& Storper, M. (1987). High technology industry and regional development: a theoretical critique and reconstruction. International Social Science Journal, 39, 215-32.

Solnit, R. (2002). Hollow city: The siege of San Francisco and the crisis of American urbanism. Verso.

Spence, M., \& Hlatshwayo, S. (2012). The evolving structure of the American economy and the employment challenge. Comparative Economic Studies, 54(4), 703-738. 
Stehlin, J. (2016) The Post-Industrial "Shop Floor": Emerging Forms of Gentrification in San Francisco's Innovation Economy. Antipode, 48: 474-493.

Storper, M., Kemeny, T., Makarem, N., \& Osman, T. (2015). The Rise and Fall of Urban Economies: Lessons from San Francisco and Los Angeles. Stanford University Press.

Timothy, D. and Wheaton, W. (2001). Intra-Urban Wage variation, Employment Location, and Commuting Times. Journal of Urban Economics, 50, 338-366.

van Dijk, J.J. (2016). Local employment multipliers in US cities. Journal of Economic Geography, lbw010.

Van Dijk J.J. (2018) Robustness of econometrically estimated local multipliers across different methods and data. Journal of Regional Science. https://doi.org/10.1111/jors. 12378

Zuk, M., Bierbaum, A. H., Chapple, K., Gorska, K., Loukaitou-Sideris, A., Ong, P., \& Trevor, T. (2015). Gentrification, displacement and the role of public investment: A literature review.

Federal Reserve Bank of San Francisco Working Paper 2015-5. 


\section{A. Data Appendix}

The following section provides further detail on the construction of our analytical dataset, detailing how we distinguish between tradable and nontradable activity; the identification of high-technology industries; and our measurement of local living costs.

\section{A1. Distinguishing tradable from nontradable industries}

As described in section 4.1, primary distinctions between tradable and nontradable activities are made using a locational Gini coefficient. Table A1 presents the lowest- and highest-scoring industries, offering the opportunity to check these results against intuition. As is evident, the least geographically concentrated sectors are largely nontradable retail, while the most concentrated represent evidently tradable sectors, mainly those that are dependent on first-nature resource allocations that are geographically uneven. The most concentrated and least concentrated thirds of the distribution of Gini coefficients by sector conforms to basic intuition, with manufacturing sectors being amongst the most geographically concentrated sectors and retail sectors amongst the least.

Distinctions in the middle of the distribution, however, are less clear, with tradable activities sitting cheek-by-jowl with nontradables and a handful of ambiguous cases. To maximize the validity of our categorization scheme, we manually examine the ranking of industries and identify ones whose Gini values do not correspond to expectations regarding tradability. For instance, NAICS 4851 Urban Transit Systems receives a Gini coefficient that places it in the immediate neighborhood of tradable sectors like Lime and Gypsum Product Manufacturing (NAICS 3274). And yet, while urban transit sustains tourism, we believe it is chiefly a locallyconsumed service. In clear cases such as these, we follow our intuition regarding industry classification. We additionally flag 18 varieties of wholesale activities, which receive a very wide array of Gini values. Unclear on their tradability, we remove these from our analytical dataset. ${ }^{12}$ Out of a total of 302 industries, these procedures leave us with 149 activities that we define as tradable, and 135 sectors defined as nontradable.

\footnotetext{
${ }^{12}$ A full list of classified industries is available from the authors upon request. We experimented with including wholesaling industries as either nontradables or as non-tech tradables and found comparable regression results.
} 
Table A1. Most- and least-geographically concentrated industries according to Locational Gini coefficients, 2015.

\begin{tabular}{cclc}
\hline Rank & NAICS & Industry Name & Gini \\
\hline 1 & 4821 & Rail Transportation & 0.9756 \\
2 & 4879 & Scenic and Sightseeing Transportation, Other & 0.7323 \\
3 & 3122 & Tobacco Manufacturing & 0.6918 \\
4 & 4861 & Pipeline Transportation of Crude Oil & 0.6576 \\
5 & 1132 & Forest Nurseries and Gathering of Forest Products & 0.6528 \\
$\vdots$ & & & \\
299 & 8111 & Automotive Repair and Maintenance & 0.0006 \\
300 & 4422 & Home Furnishings Stores & 0.0006 \\
301 & 6211 & Offices of Physicians & 0.0005 \\
302 & 4451 & Grocery Stores & 0.0005 \\
303 & 6212 & Offices of Dentists & 0.0002 \\
\hline
\end{tabular}

Note: Authors' calculations of Gini coefficients based on 4-digit QCEW data for 2015. A full list of classified industries is available from the authors upon request.

\section{A2. Identifying high-technology industries}

As described in section 4.2, we use BLS guidance on what constitutes high-technology activities, using the strictest of the criteria adopted. Table A2 provides a list of these industries, along with annual wages in 2015.

Table A2. Level 1 High-Technology Industries

\begin{tabular}{llc}
\hline NAICS & Industry & $\begin{array}{c}\text { Wages } \\
(2015)\end{array}$ \\
\hline 3254 & Pharmaceutical and medicine manufacturing & $\$ 123,811$ \\
3341 & Computer and peripheral equipment manufacturing & 164,648 \\
3342 & Communications equipment manufacturing & 104,034 \\
3344 & Semiconductor and other electronic component manufacturing & 100,161 \\
3345 & Navigational, measuring, electromedical, and control instruments manufacturing & 96,558 \\
3364 & Aerospace product and parts manufacturing & 96,795 \\
5112 & Software publishers & 147,045 \\
5179 & Other telecommunications & 88,624 \\
5191 & Other information services & 166,765 \\
5182 & Data processing, hosting, and related services & 98,616 \\
5413 & Architectural, engineering, and related services & 86,405 \\
5415 & Computer systems design and related services & 106,613 \\
5417 & Scientific research-and-development services & 129,553 \\
\hline
\end{tabular}

Note: Information drawn from Hecker (2005), Table 1. The table has been updated to reflect 2015 annual wages using data from QCEW. Hecker originally defines high-technology activities as including NAICS codes 5161, Internet Publishing and broadcasting and 5181, Internet service providers and Web search portals. In 2007, the Census Bureau merged these categories into code 5191, 'Other information services,' a category which is predominantly made up of 5-digit NAICS code 51913, Internet Publishing and Broadcasting and Web Search Portals. 


\section{A3. Nominal and Real Incomes}

Recent efforts have been made to construct consumer price indices that reflect subnational differences. Moretti (2013) constructs two such measures, one capturing local differences in the cost of housing, the other additionally reflecting local variation in nonhousing costs. Meanwhile, the Federal government has released Regional Price Parities that cover housing and non-housing components for 38 large metropolitan areas in selected years (Bureau of Economic Analysis, 2016). Given the less-than-comprehensive nature of the latter, and given broad consistency across approaches reported in Moretti (2013), we opt to mimic the simpler of Moretti's methods to estimate our own annual local consumer price indices. According to the BLS methodology, 'housing' includes direct costs like rent, but also indirect expenditures on heating and other utilities. It is the largest single component of the national Consumer Price Index for All Urban Consumers (CPI-U), representing approximately 40 percent of the total expenditures. On this basis, and because housing markets are much more localized than, say, markets for food and clothing, we allow the price of housing to vary from one locality to the next, while our accounting of non-housing costs is derived from the national CPI-U. To account for the role of housing in consumer expenditures, we follow common practice in using rental information rather than the prices faced by home buyers. Home prices combine the value of a consumption good, as well as future investment expectations. As such, it is less suitable than rents in capturing the actual use-value of housing (Poole et al, 2005). 